\title{
Treatment strategy of allergic rhinitis in the face of modern world threats
}

\author{
Piotr Rapiejko', Dariusz Jurkiewicz', Wioletta Pietruszewska², Beata Zielnik-Jurkiewicz'3 , Jarosław Woroń45, \\ Agnieszka Lipiec ${ }^{6}$
}

'Department of Otolaryngology with Division of Cranio-Maxillo-Facial Surgery in Military Institute of Medicine, Warsaw, Poland

2Department of Otolaryngology and Laryngological Oncology. Medical University of Lodz, Poland

${ }^{3}$ ENT Department, Children's Hospital, Warsaw, Poland

${ }^{4}$ Chair of Pharmacology, Dept. of Clinical Pharmacology Jagiellonian University College of Medicine, Krakow Poland

EUniversity Hospital in Krakow

${ }^{6}$ Department of Prevention of Environmental Hazards and Allergology, Medical University of Warsaw, Poland

\author{
Article history: Received: 15.02.2018 Accepted: 28.03.2018 Published: 30.04.2018
}

ABSTRACT: $\quad$ Allergic rhinitis (AR) is the most common form of allergy, which - as epidemiological research has shown - applies to nearly $25 \%$ of the population. AR significantly affects the quality of life of the patient, and the more severe the disease, the greater the risk of developing bronchial asthma. One of the factors affecting the severity of symptoms and the degree of their control is air pollution. In some patients, despite proper treatment, persistence or only partial remission of symptoms (uncontrolled allergic rhinitis) is observed. This can lead to an increase in comorbidities - inflammation of the paranasal sinuses, otitis media and asthma - both in children and in adults. The treatment of allergic rhinitis, in accordance with the standards, consists in: education of the patient, elimination of the allergen from the environment and factors intensifying the course of the disease, selection of proper pharmacotherapy and specific allergen immunotherapy. Many factors influence the selection of the antihistamine used, e.g., the opportunity of safe increase of the dosage.

KEYWORDS: $\quad$ allergic rhinitis, air pollution, treatment, uncontrolled allergic rhinitis, antihistamines, dose escalation, fexofenadine

\section{ALLERCIC RHINITIS - EPIDEMIOLOCY AND SYMPTOMATOLOGY}

Allergic rhinitis (AR) is a set of clinical symptoms caused by an IgE-mediated inflammatory reaction of the nasal mucosa to the allergen. This disease affects approximately $17-29 \%$ of the European population, and some studies report that AR is the most frequent atopic disease in developed countries $(40 \%$ in children and $30 \%$ in adults) $[1,2]$. The last Polish population-based study ECAP (Epidemiology of Allergic Diseases in Poland) showed that more than $35 \%$ of residents of large cities reported rhinitis, and $21 \%$ of young adults, almost $25 \%$ of adolescents and $24 \%$ of children reported symptoms of AR. In the rural population, this percentage was lower and amounted to $16 \%$ [3]. Nasal infections significantly increase the risk of asthma. The coexistence of nasal congestion was reported by as much as $73.6 \%$ of people with bronchial asthma [3]. Rochat et al. [4] confirmed that the occurrence of allergic rhinitis until the age of 5 increased by almost 4 times the probability of bronchial asthma after the age of $13(\mathrm{OR}=3.82, \mathrm{p}<0.01)$. It is extremely important for a physician that the symptoms of AR negatively affect the quality of life of patients $[5,6]$.

Allergic rhinitis is an inflammatory disease of the nasal mucosa and is characterized by the presence of at least one of the symptoms: nasal obstruction; sneezing; nasal pruritus and rhinorrhea. Symptoms that last less than 4 days a week and for a total of less than 4 weeks a year are defined as periodic, and those that last longer - as chronic [2,5]. Nasal symptoms are very often accompanied by the symptoms of allergic conjunctivitis: swelling, redness of the conjunctiva, tearing and itching of the eyes. The document ordering the classification of allergic rhinitis and indicative methods of diagnostic and therapeutic procedures is ARIA (Allergic Rhinitis and its Impact on Asthma) with two updates - in 2010 and a summary after 10 years of existence, in $2012[2,6]$. ARIA indicates a close relationship between the oc- 
currence of AR and the development and comorbidity of bronchial asthma [8]. The previous classification dividing AR into seasonal and perennial, and thus based on the time of exposure to allergens, was insufficient to assess and plan treatment in patients with AR. The new classification takes into account the symptoms, quality of life, duration of symptoms and severity of the disease (tab. 1). The patient may therefore suffer from AR with periodic or chronic symptoms, and the severity of symptoms may be mild or moderate/severe. Periodic allergic rhinitis is usually caused by allergens of short-term pollens or periodic exposure to animal allergens or molds. However, the causes of chronic AR are usually allergens from the home environment: mites, molds, and allergens of animal origin.

The severity of symptoms is closely related to the degree of exposure to the causative agent and its concentration in the environment. For the Polish population, the thresholds for the concentration of pollen of various plant species, which cause allergic symptoms in people allergic to specific allergens have been determined [9]. It was also shown that the severity of allergic rhinitis is not only influenced by exposure to allergens, but also by the degree of air pollution [10].

Due to the severity of symptoms, we divide AR into: mild, moderate and severe. In mild AR, the symptoms are marginal and do not significantly affect the quality of life and the daily functioning of the patient seeking medical help. Moderate AR manifests itself as a deterioration of the average quality of life, and the disease affects everyday functioning (work, study, sports, social life), as well as sleep. In this situation, the patient is determined to undertake treatment. In severe AR, symptoms significantly limit everyday functioning, reducing productivity at work, learning outcomes and quality of life. They also significantly impair sleep, and the patient is determined to begin treatment, and sometimes even forced to do so.

\section{THE EFFECT OF AIR POLLUTION ON THE SEVERITY OF SYMPTOMS AND THE DEGREE OF CONTROLOFAR}

One of the most important threats to the modern world is air pollution with substances harmful to human health and the environment. It is estimated that around 92\% of the world's population live in areas where WHO standards for air quality are not met [11]. Although in Europe, the situation regarding air quality is gradually improving, Poland still belongs to countries with a high degree of air pollution $[12,13]$.

In Poland, sources of pollution emission have changed in recent years, concentrations from the so-called low emissions
Tab. I. Distribution of allergic rhinitis according to ARIA 2010

\begin{tabular}{|c|c|c|}
\hline CRITERIA & DIVISION OF RHINITIS ACCORDI & JG TO ARIA \\
\hline $\begin{array}{l}\text { Duration of } \\
\text { symptoms }\end{array}$ & $\begin{array}{l}\text { Periodic } \\
\text { Symptoms: } \\
\text { - <4 days a week } \\
\text { - or <4 weeks. }\end{array}$ & $\begin{array}{l}\text { Chronic } \\
\text { Symptoms: } \\
\text { - >4 days a week } \\
\text { - and/or }>4 \text { weeks.. }\end{array}$ \\
\hline $\begin{array}{l}\text { Severity of } \\
\text { symptoms }\end{array}$ & $\begin{array}{l}\text { Mild } \\
\text { - no sleep disorders } \\
\text { - no physical activity } \\
\text { disorders } \\
\text { - no negative effect on } \\
\text { life activity (school, } \\
\text { work) } \\
\text { - no symptoms impairing } \\
\text { quality of life. }\end{array}$ & $\begin{array}{l}\text { Moderate/severe } \\
\text { - sleep disorders } \\
\text { - impairment of physical } \\
\text { activity } \\
\text { - negative influence on life } \\
\text { activity (school, work) } \\
\text { - symptoms impairing } \\
\text { quality of life. }\end{array}$ \\
\hline
\end{tabular}

have increased [12], i.e., from pollutants introduced into the air from emitters of a height below $40 \mathrm{~m}$. The source of these pollutants are households, low-powered boiler houses and public buildings. The emission of pollutants from communication and transport also plays an important role. Emission of solid particles, which form a large part of particulate matter (PM) in urban agglomerations, is a phenomenon characteristic of Diesel engines. The so-called fugitive emissions caused by fires, field work and industrial failures also play an important role. Pollutant emission is the basis of the smog phenomenon [13].

The biggest source of pollution is the combustion of fuels, which releases products of incomplete combustion into the environment. Over $75 \%$ of the total dust emission (including fine particulate matter PM 10, PM 2.5), NOx and SO2, approx. 70\% of $\mathrm{CO}$ emission and $90 \%$ emission of $\mathrm{CO} 2$ comes from these sources. They are also responsible for the emission of particularly polycyclic aromatic hydrocarbons (PAH), dioxins, furans (PCDD/Fs), soot and heavy metals that are particularly harmful to health. Small dust adsorbs toxic chemicals on its surface: carbon black, benzopyrene and other polycyclic aromatic hydrocarbons (PAH), polychlorinated dioxins and furans (PCDD/Fs), polychlorinated biphenyls (PCBs) and other organic compounds of nitrogen, sulfur, chlorine and oxygen [13].

The most serious source of pollution inside dwellings are the products of combustion of fuels used for space heating, food preparation as well as tobacco smoke. At the same time, air quality is influenced by the type of ventilation, technical condition and equipment of the flat. Harmful substances are released from building materials, those used for interior decoration, as well as cleaning agents used.

Available research results indicate the negative health effects of air pollution both outside and inside the home environment [11, 14]. They have a significant impact on the frequency and course of chronic and acute respiratory diseases, including allergic diseases. 
Well-documented are the health effects of particulate matter with aerodynamic diameter $\leq 10 \mu \mathrm{m}$ (PM 10) which may reach the lower respiratory tract, fine dust $\leq 2.5 \mu \mathrm{m}$ (PM 2.5) irritating the respiratory tract, penetrating the lungs and particles with aerodynamic diameter $\leq 1.0 \mu \mathrm{m}$ (PM 1) that can penetrate into the alveoli and reach the blood stream $[13,15]$. Recent reports indicate that smaller particles - up to $0.2 \mu \mathrm{m}$ in diameter - cause oxidative stress and inflammatory reactions [16]. Impaired nasal patency in the course of rhinitis (including AR) deprives the lower respiratory tract of protection that would be a properly functioning nose (performing, among others, filtration function).

Mechanisms of the impact of air pollution on health are subject to numerous tests. One of the adopted theories is the one about the body's response to many stimuli acting simultaneously (the so-called summation of stimuli mechanism) [15].

Air pollution is one of the important elements that explain the higher incidence of allergic rhinitis in the inhabitants of urban agglomerations compared to the inhabitants of rural areas [17]. In people with hypersensitivity, exposure to impurities increases the response of the nasal mucosa to inhalation allergens. They can induce or increase inflammation in the respiratory mucosa and increase hyper-reactivity [18].

Analysis of research carried out in 12 countries - research, which covered over 45 thousand children - showed that prolonged exposure to suspended dust increases the risk of chronic respiratory symptoms. There was a statistically significant relationship between the average concentration of suspended PM 10 particles in the air near the children's place of residence and the occurrence of allergic rhinitis and morning cough and sputum production [19].

Gas pollution, including ozone and nitrogen dioxide also have a significant impact on health. Air pollution with ozone (O3) recorded mainly in urban areas and being a component of the so-called "summer smog" - is responsible for reducing the efficiency of the respiratory system, increasing the hyperresponsiveness of the bronchial tree and triggering oxidative stress [20]. Exposure to high concentrations of ozone exerts a priming effect, which: sensitizes the mucous membrane of the airways to allergens, enhances the inflammatory effect in the airways and facilitates the penetration of inhalation allergens through the airway mucosa, enhancing the release of pro-inflammatory mediators [19]. The results of epidemiological studies indicate that exposure to nitrogen dioxide is associated with an increased incidence of both allergic rhinitis and bronchial asthma [21]. Analysis of research works in 5 European countries and Russia, which included over 23 thousand children, showed a statistically significant relationship between NO2 exposure in atmospheric air and symptoms of inhalation allergy [22].

Particular importance from the point of view of allergy is attributed to solid particulate matter emitted by Diesel-exhausted particles (DEP) [23]. It is believed that the toxic effect of DEP is associated with particles that have an aerodynamic diameter of less than $10 \mu \mathrm{m}$ (PM 10). Exposure to these molecules is a known risk factor for the development of bronchial asthma and allergic rhinitis. It results in an increased risk of inhalation allergy in both children [24] and adults [25]. It is known that DEPs induce inflammatory reactions in the airways, cause disorders of aerobic metabolism in cells, leading to the formation of oxygen free radicals and the formation of so-called oxidative stress in the cell. Oxidative stress and inflammatory reactions result in cell damage [18]. In addition, DEP exerts an adjuvant effect on the synthesis of IgE in people with atopy, thus affecting the state of hypersensitivity to inhalation allergens [20]. Study results that indicate the role of DEP in increasing Th-2 of the dependent response of the immune system, and thus promoting allergic reactions are available [26]. In the same mechanism, allergic reactions can be promoted by components of cigarette smoke, which pollutes the air [18]. What's more - exhaust gases of diesel engines can adsorb the aeroallergens released by plant pollen. By stopping them in the air, they intensify the IgE-dependent response [20]. The results of a Polish study conducted by Porębski et al. showed a relationship between an apartment in the immediate vicinity of communication arteries and an increase in the frequency of inhalant allergy in children [27].

Among the particles suspended in the air are also pollen grains, mushroom spores and other particles that are the carrier of allergens. Environmental pollution can increase the allergenicity of natural allergens by interacting with them, inducing non-specific over-reactivity of tissues and organs. Increasing the allergenicity of pollen from plants that occupy positions in the immediate vicinity of high-speed routes was confirmed for ragweed pollen [28] and for birch pollen growing in an atmosphere characterized by high ozone concentration [29].

Thus, air pollution can affect both the occurrence and severity of symptoms and the degree of allergic control of rhinitis by affecting the intensity of pollen grain production by sensitizing plants and the modification of their allergenicity [30].

\section{UNCONTROLLED UPPER RESPIRATORY TRACT DISEASE: ALLERGIC RHINITIS (AR) AND CHRONIC SINUSITIS (CS)}

In some patients, despite proper treatment of AR, there is 
either persistence or partial resolution of the symptoms. Following the GINA consensus (concerning bronchial asthma), a concept of a treatment regimen with patients with AR and CS was developed. It defines the degree of the disease, dividing it into controlled, partially controlled and uncontrolled. This is important in order to define a group of patients who are difficult to treat, and are a diagnostic and therapeutic challenge, whose therapy is an important socio-economic aspect. Defining factors affecting lack of disease control would translate into improved effectiveness of treatment of the so-called common respiratory disease [31]. In EPOS [32,] it has been the first time features were defined which testify to the control of chronic rhinosinusitis, including AR. Their development may create opportunities for new research that would indicate the mechanisms responsible for the lack of disease control. This would translate into practical treatment in selected groups of patients. Controlled disease is defined as a condition in which the patient either has no symptoms of the disease or the symptoms are not bothersome. In AR and CS, symptoms of the disease are a consequence of inflammatory reactions of the mucous membrane, therefore their control would be directed to anti-inflammatory therapy. Retrospective studies in patients with AR showed that almost $20 \%$ of patients are not satisfied with the therapy and assess their symptoms in the visual analogue scale (VAS) at the level of 5 points or above. A cut-off at the level of 5 points has been proposed for the definition of uncontrolled disease [1].

Strict adherence to ARIA criteria for patients with AR causes a lower incidence of uncontrolled AR (10\%) compared to any other treatment (18\%). However, the use of the VAS scale for the assessment of nasal symptoms in AR proved to be a useful tool in assessing the degree of disease control and translated into a validated quality of life questionnaire $[1,33]$.

In the ARIA and EPOS consensus - in accordance with the proposed algorithms of conduct - it is recommended to evaluate the effectiveness of treatment after 2-4 weeks for AR and after 3 months for CS The latest editions of consensus [1, 32] propose a control of the effectiveness of treatment in AR after 2 weeks.

In patients who do not have disease control despite proper diagnosis and treatment, an attempt was made to determine the factors affecting this situation. These factors were divided into four groups: 1) related to the disease, 2) related to the diagnosis, 3) related to the patient, 4) related to the treatment used. The first group includes environmental factors: allergen concentration, exposure to tobacco smoke, environmental pollution, irritants in the workplace. Hormonal factors that are usually associated with a more severe allergic inflammatory reaction are worth stressing - about $30 \%$ of women present a worse to- lerance of allergy symptoms during pregnancy. A genetically determined response to irritants may disturb the balance between the secretion of proinflammatory and anti-inflammatory proteins, as well as the individually conditioned hyperreactivity of the mucous membrane. Neurological mechanisms in patients with AR may also result in increased secretion of mediators, e.g., substance P and others. In a group of patients, as in bronchial asthma, steroid resistance is described in patients with AR and sinusitis [34]. The inflammatory process of the nasal mucosa and paranasal sinuses in the course of AR may exacerbate numerous environmental and hormonal factors. The base of uncontrolled CS may be - in addition - immunity disorders, ciliary epithelial dysfunction and genetic diseases, such as cystic fibrosis.

\section{UNCONTROLLED ALLERGIC RHINITIS IN CHILDREN AND ADOLESCENTS}

Allergic rhinitis (AR) is not a benign disease because, if it is not adequately controlled, it can lead to worsening of other diseases such as rhinosinusitis, otitis media and asthma. A chronic disease, such as AR in the uncontrolled phase, affects the quality of life (QOL) of children during their growth and development, because it adversely affects their daily lives. Symptoms of uncontrolled AR (UAR) can cause sleep disturbances, fatigue, attention deficit disorder, and limitations in performing daily activities [35]. The incidence of uncontrolled AR increases with the incidence of AR, so its effective treatment is very important [36].

The chronic disease that uncontrollable AR undoubtedly is in children and adolescents, is often not recognized and treated inappropriately. AR is limited not only to the physical symptoms of the nose and eyes, but also causes disorders in the overall well-being of patients. Uncontrolled AR significantly affects the quality of life of children and adolescents. Children with uncontrolled AR avoid more school activities than their healthy peers, show signs of fatigue, have cognitive impairment, often have mood disorders (anxiety, depression, emotional disturbances), which is the basis for recognizing ,angry child" syndrome. In children with uncontrolled AR, sleep disorders occur, and in the case of chronic forms, social functioning disorders are often found. This disease, especially when it is undiagnosed and/or poorly treated, also adversely affects the results of learning.

Poor quality of sleep causes drowsiness during the day, fatigue, cognitive limitations and, as a result, difficulties in learning. Children with AR are often shy, depressed, restless, and sometimes even scared. In addition to the impairment of social and 
physical functioning, uncontrolled AR can significantly change the quality of life of patients, as well as their performance and learning ability [37-39]. The intensity of symptoms does not necessarily correlate with the degree of impairment of quality of life, so the choice of effective treatment requires an individual approach to each patient [39-41].

The intensity of UAR symptoms is more important than their duration, which in turn affects sleep quality and learning outcomes. The physical, psychological and social limitations associated with nasal obstruction and sneezing cause irritation - small patients do not sleep well at night, so their body often loses strength during the day.

In UAR, „non-nasal” symptoms also increase, which causes discomfort. For example, excessive thirst, greater difficulty in concentrating (especially at school), as well as frequent headaches that - resulting in limitations in everyday life - cause frustration and irritability.

Sleep disturbances can affect the quality of life. They cause tiredness, irritability, memory defects and drowsiness during the day [37]. Fragmentary sleep, in addition to increased sleepiness during the day, worsens cognitive performance. Sleep disorders also have a significant impact on mental health and can cause mental illness, depression and anxiety [42].

Respiratory disorders associated with abnormal, interrupted sleep in the course of UAR during puberty, are associated with a higher incidence of learning difficulties and attention [43, 44]. Proper treatment of uncontrolled AR may have a beneficial effect on improving the quality of sleep, and thus reducing any secondary limitations to sleep disorders $[45,46]$.

In children with uncontrolled AR, functional features - i.e., memory and learning - can be disturbed, which significantly affects the intellectual results. If the symptoms are not adequately controlled, they can cause learning problems by disturbing the quality and amount of sleep at night, resulting in daytime fatigue [47].

Children with uncontrollable AR may feel complete isolation, even in their families, because the presence of allergens often makes it difficult for them to participate in daily activities, weekend and holiday trips, and also prevents playing with animals [48]. At school, they may display emotional disorders caused by learning difficulties or limited activity resulting from the need to avoid contact with allergens. As a result, children with UAR are not able to achieve full and unrestricted integration with their peers, which contributes to the formation of emotional distortions. They complain of headaches, fatigue, are inefficient and unable to concentrate at school. Conjunctivitis, usually associated with uncontrolled UAR, may impair their visual acuity and therefore interfere with activities that require good vision.

In the case of young children with UAR, their absence from school may also affect the performance of their parents' work (through the need to take their days off) [39].

\section{PRINCIPLES OFTHERAPEUTIC TREATMENT IN AR}

Basic principles of treatment of allergic rhinitis according to ARIA [1, 2, 6, 7] and PoSLeNN [5] include:

- allergen avoidance (whenever possible)

- education of the patient and his family (always)

- specific allergen immunotherapy (conducted by a specialist)

- pharmacotherapy, which is to be safe, effective and easy to use.

The aim of the therapy is both the removal of local symptoms, blocking the inflammatory allergic reaction, as well as comprehensive treatment including the elements of pharmacological prophylaxis and reduction of exposure to allergens.

Treatment of allergic rhinitis should start with an attempt to eliminate the allergen from the patient's environment, or at least reduce the exposure to the allergen that causes symptoms.

In the treatment of acute symptoms of AR (sneezing, watery runny nose, itching in nose or eyes) first-line treatment, due to the speed of action, are oral and nasal antihistamines. In the case of concomitant impairment of nasal patency, short-term use of alpha-mimetic drugs (locally or generally) and intranasal glucocorticoids is necessary.

\section{CHOICE OF ANTIHISTAMINE IN THE TREATMENT STRATECY OF UNCONTROLLED AR}

In the group of antihistamines, from a practical point of view, of highest significance are pharmacokinetic interactions that take place at the metabolic stage and are carried out with the participation of cytochrome P450 isoenzymes. Therefore, it is very important to consider the criterion of non-metabolism mediated by cytochrome P450 when choosing a drug from this group. The importance of this criterion was appreciated by the bodies which formulate recommendations regarding the treatment of patients with both AR (ARIA 2010) and urtica- 
ria (EAACI 2013). The lack of metabolism through cytochrome P450 is mentioned as important in the choice of the drug.

Cytochrome P450 exhibits monooxygenase activity. It is common in almost all tissues, however it displays the highest activity in the liver and adrenal medulla. Cytochrome P450 is an important element in the metabolism of drugs, especially of hydrophobic character. Metabolism products are usually more hydrophilic than substrates, which promotes their further metabolism and excretion. Most forms of cytochrome P450 display low specificity to the substrate, catalyzing the transformation of many different substances. It is worth remembering that the biotransformation of drugs occurs mainly in hepatic microsomes, which have active enzymatic systems that show the ability to metabolize such endogenous (e.g., cholesterol, steroid hormones, fatty acids), as well as exogenous compounds (e.g., drugs).

To a lesser extent, biotransformation reactions involving enzymes also take place in the gastrointestinal mucous membrane, nasal cavity and lungs, however, the role of drug metabolism in these areas is currently not fully known.

In the case of medicines administered orally, biotransformation is a complex process, because drugs absorbed from the gastrointestinal tract enter the bloodstream almost exclusively through the portal circulation system. In clinical practice, CYP3A4, CYP2D6, CYP1A2, CYP2C9, CYP2C19 have the greatest practical significance due to the risk of interactions.

It should also be taken into consideration that there is a group of individual factors specific to individual patients that can influence the biotransformation processes of drugs, including the speed of these processes.

The following factors are of greatest importance in clinical practice:

- genetic - they determine the body's ability to quickly or slowly metabolize certain drugs;

- gender - in men, drugs are metabolized much faster than in women, probably as a result of the stimulating effect of testosterone on the activity of enzymes found in the membranes of the endoplasmic reticulum of liver cells;

- age - decreased activity of microsomal enzymes in newborns and older people;

- pathological states of organs responsible for drug metabolism, among others liver and kidneys - it leads to impaired biotransformation of drugs and prolonging of their duration of action, in the case of which the accumulation of drugs is also possible;

- route of administration - increased liver metabolism of certain drugs after oral administration (the so-called first pass effect);

- pregnancy - can induce CYP enzymes, an example of which is the potential induction of CYP2D6 observed by the increased biotransformation of drugs metabolized by this isoenzyme;

- inflammatory processes - acute inflammatory factors inhibit CYP activity in humans, which may lead to abnormally high plasma concentrations and increased toxicity of drugs metabolized by cytochrome P450 isoenzymes;

- nutritional status - both malnutrition and obesity affect CYP activity;

- cigarette smoking - induces CYP enzymes, especially CYP 1A2 isoenzyme

- When choosing an antihistamine, it is worth taking into consideration the potential risk of adverse interactions between antihistamines and other drugs that the patient is taking simultaneously. This risk undoubtedly grows when the antihistamine used is metabolized with the participation of cytochrome P450. In order to prevent drug interactions and their clinical consequences, and at the same time to modify treatment, drugs that are not metabolized by CYP 450 should be selected. And this is also emphasized by the recommendations cited earlier.

- One can even say that the risk of interaction in polytherapy is the most important criterion for choosing an antihistaminic drug.

Among chronic diseases, allergic diseases and bronchial asthma are in a group, which particularly increases the risk of polypharmacy (a situation in which the patient accepts more than several drugs at the same time). In the available pharmacoepidemiological studies, it has been demonstrated that the risk of excessive polytherapy increases 4.5 times in people with allergic diseases. The risk of significant polytherapy is particularly high in the treatment of cardiovascular disease, analgesia and in the treatment of allergic diseases.

The comprehensive treatment model significantly increases the risk of polytherapy. The more doctors participate in the therapy, the greater the risk of polypharmacy, which is most often associated with the lack of coordination of the recommended preparations, and in particular the lack of coordination of pharmacotherapy as part of the family doctor's care or pharmaceutical care. The phenomenon of polypragmasy is also intensified by the cascade of prescribing drugs, a phenomenon described in the literature from the late 1990s. of the 


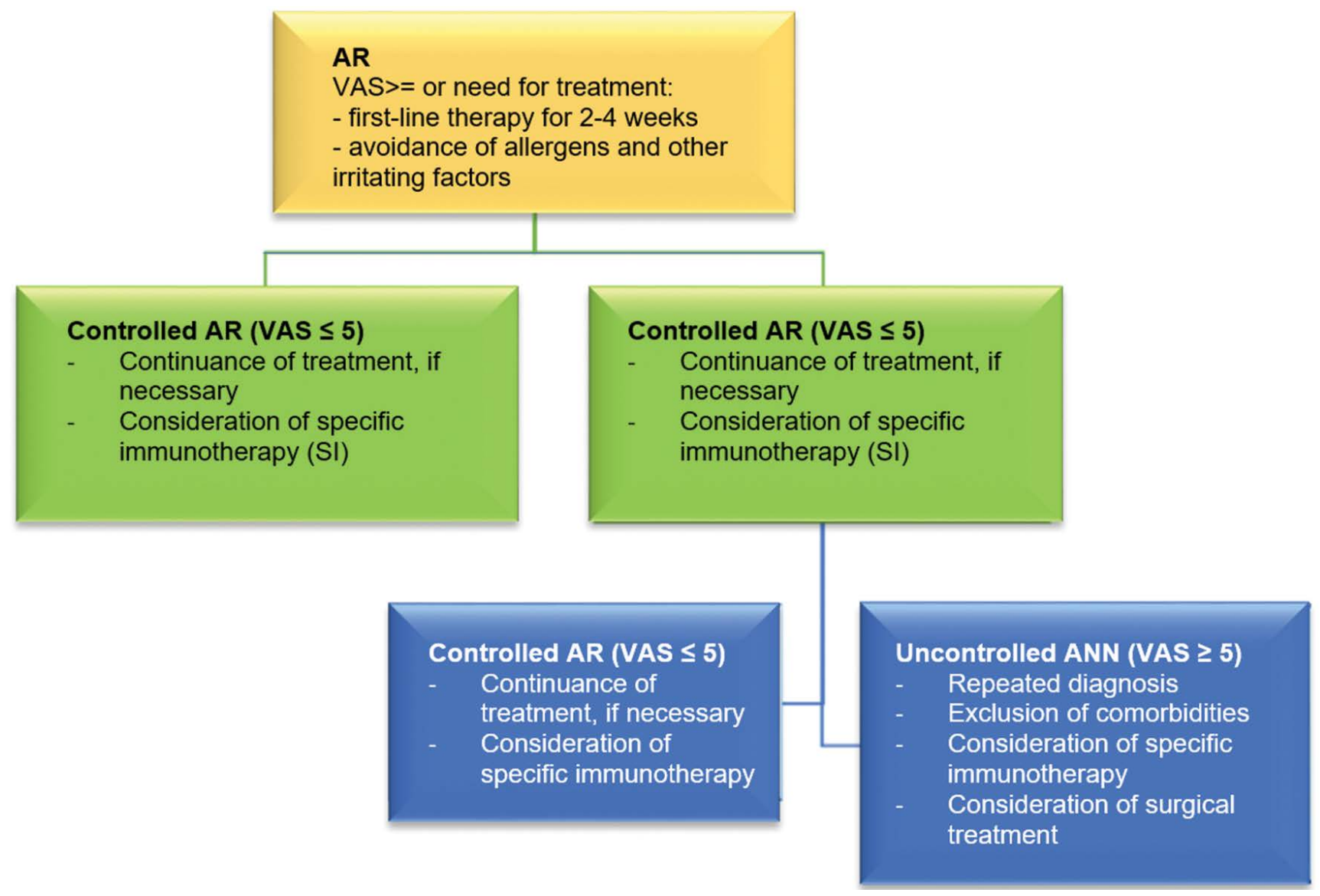

Fig. 1. Algorithm for treatment of patients with uncontrolled allergic rhinitis (UAR) based on ARIA consensus in own modification along with a proposal to increase the dose of antihistamine.

twentieth century. The prescription cascade occurs when an undesirable symptom resulting from the treatment is treated as a sign of a new condition and causes the introduction of another pharmacological preparation. This is often the case of side effects induced by antihistamines. In many cases, there is also a shortage of health professionals' knowledge on the interaction of drugs. It is therefore worth looking at the differences in the induction of interactions with other concomitant medications in patients who are also taking antihistamines. It is worth remembering that the lowest risk of interactions between drugs used in polytherapy is related to the use of bilastine and fexofenadine.

In pharmacotherapy of allergic rhinitis, one of the most important clinical problems is the right choice of an antihistaminic drug. Both the strategy and the relatively long time of administration of antihistamines mean that the applied preparation should be characterized by high efficiency and safety. This is due, among other things, to the fact that the standard dose of antihistamine does not always show optimal therapeutic efficacy, which results in the doctor escalating the dose, in the case of over-the-counter medications. The use of drugs that in addition to the $\mathrm{H} 1$ receptor activity also affect cholinergic or adrenergic receptors may result in adverse reactions [49]. While in the case of urticaria we have data, and moreover standards that allow the use of a 4-fold higher dose of the drug, as already mentioned - there is no such data in the treatment of AR. Therefore, in patients with uncontrolled allergic rhinitis, in whom we may consider the need to increase the dose of the drug, it is necessary to choose preparations with high safety. It is also worth remembering that AR often coexists with other diseases, which requires taking into account the interaction between antihistamines and other concomitant preparations. The antihistamine that is used to treat AR should be characterized by:

- high selectivity for the H1 receptor,

- lack of penetration of the blood-brain barrier, and 
therefore the absence of sedative action, which is dosedependent and one of the most common reasons for discontinuation of treatment, as well as the need to transfer to another antihistamine,

- lack of anticholinergic activity, which can both increase sedation and impair the functioning of the patient,

- lack or low risk of interactions with other concomitant medications,

- optimal pharmacokinetic profile [49-51].

One of the drugs that meets all the characteristics described is fexofenadine. It is a derivative of butyrophenone with a strong antihistamine effect, it is characterized by high affinity to the $\mathrm{H} 1$ receptor at low dissociation constant, which in practice means high antihistamine activity. It is a pharmacologically active metabolite of terfenadine, a specific, selective and potent antagonist of the peripheral histamine $\mathrm{H} 1$ receptor. Fexofenadine is characterized by an optimal pharmacokinetic profile in comparison to other antihistamines available on the market. The antihistamine action of fexofenadine starts one hour after administration, reaches a maximum after 6 hours and lasts up to 24 hours, which makes the drug convenient to dose, and its long half-life guarantees a stable antihistamine effect, so important in patients treated for AR. Fexofenadine does not penetrate the blood-brain barrier to a small extent and does not show either a sedative or clinically relevant anticholinergic effect, which is associated with very good tolerability of the treatment [52-54]. Unlike terfenadine, fexofenadine does not inhibit the potassium channel with delayed influx, which plays an important role in the repolarization of heart cells. As a result, fexofenadine does not exert any cardiotoxic activity and does not cause cardiac arrhythmias, which sometimes occur with terfenadine (which is why it was withdrawn from the pharmaceutical market). Fexofenadine increases the electrical resistance of cells, which is associated with decreased cell membrane permeability and is an important pleiotropic effect in patients with AR. It also reduces the release of proinflammatory factors triggered by eosinophils from epithelial cells of the nasal mucosa, such as: IL-8, GM-CSF and sICAM-1. It significantly reduces the chemotaxis of eosinophils and their adhesion to the endothelium. It also affects the inflammatory processes in allergic rhinitis [51,53-55]. It absorbs quickly from the gastrointestinal tract (tmax is $1-3$ hours).

The pharmacokinetics of fexofenadine are linear in nature, which in practice means that the need to increase the dose of a drug in a patient with AR guarantees a directly proportional increase in the effect depending on the dose used. It binds to plasma proteins at a level of 60-70\% [51]. During long-term use $t 1 / 2$ is $11-15$ hours. Metabolism is slightly affected. Elimination occurs mainly in the bile, and up to $10 \%$ is removed in unchanged form in the urine, which is also an important element in the choice of the drug in patients with co-morbidities, including in patients with impaired renal function [51].

When choosing an antihistamine, it is worth taking into consideration the potential risk of adverse interactions between antihistamines and other medicines taken simultaneously by the patient. This risk undoubtedly grows when the antihistamine used is metabolized with the participation of cytochrome P450. In order to prevent drug interactions and their clinical consequences, and the need to modify the treatment, drugs that are not metabolized by CYP 450 should be selected. Fexofenadine has a low risk of interactions with other concurrently used drugs $[52,53]$. One can even say that the risk of interaction in polytherapy is the most important criterion for choosing an antihistaminic drug.

Among chronic diseases, allergic diseases and bronchial asthma are in a group, which particularly increases the risk of polypharmacy [51-53]. In the available pharmacoepidemiological studies, it has been demonstrated that the risk of excessive polytherapy in people with allergic diseases increases 4.5 times $[51,53]$. The comprehensive treatment model significantly increases the risk of polytherapy. It is worth remembering the group of antihistamines includes a diversified risk of interaction, which is related to the characteristics of individual antihistamines [51].

Many meta-analyses indicate that fexofenadine is devoid of sedation, which is most likely due to the affinity of P-glycoprotein, which is a specific controller for the passage of xenobiotics across the blood-brain barrier [49, 51]. Fexofenadine is characterized by high cardiac safety and even at a daily dose of $240 \mathrm{mg}$ does not affect the length of QTc. It is one of its features that allows for increase of the dose, when the standard use does result in a satisfactory symptomatic effect $[49,51,55]$. In practice, it is worth remembering that fexofenadine should not be taken with strong CYP3A4 inhibitors, e.g. clarithromycin and with antacids, which may reduce the absorption of the drug from the gastrointestinal tract $[51,53]$.

The consensus of the panel of experts from Asian countries, based on the ARIA and EAACI guidelines on treatment of AR published in 2017, proposes the principles of individual selection of the optimal second-generation antihistamine drug in the treatment of AR and urticaria, depending on the patient's needs and preferences. The most important factors that should be taken into consideration when selecting the optimal antihistamine drug are: a favorable ratio of the effectiveness of the preparation to its safety, no side effects from the circulatory and nervous systems, as well as the lack of interaction with other drugs. In relation to the above factors, among second genera- 
tion antihistamines, bilastin and fexofenadine were considered to be the first choice in the treatment of both AR and urticaria. With individual selection of the drug to the needs of patients with co-existing renal and/or hepatic insufficiency, these preparations are optimal [56]. Fexofenadine is also the preferred antihistamine in accordance with the guidelines of ARIA and EAACI/GALEN/WAO $[6,57]$.

Fexofenadine is available in Poland in two doses: $120 \mathrm{mg}$ tablets (for symptomatic treatment of seasonal AR) and $180 \mathrm{mg}$ tablets (for symptomatic treatment of chronic idiopathic urticaria).

\section{SUMMARY}

Current treatment of AR in the majority of patients is effective. Its main purpose is both short- and long-term symptom con- trol. In AR, the VAS scale is a very useful tool for the control of nasal symptoms, while the use of the disease criteria proposed in the ARIA consensus makes it possible to control the disease. For patients who do not receive treatment, consideration should be given to factors that may affect the exacerbation associated with the disease itself: exposure to environmental factors, response to the treatment used, and patient compliance. In the relief of symptoms of uncontrolled seasonal allergic rhinitis, periodic increase in the dose of antihistamine appears to be justified. Obtaining the control of symptoms of AR with an increased dose of antihistamine may be the result of the patient's decision in the course of self-medication. It may also result from the decision of the doctor, including new generation antihistamines that do not cause sedation, enabling active family and professional life. In this case, it is worth using these preparations, which are also available in a higher dose next to the standard dose.

\section{REFERENCES}

1. Bousquet J., Khaltaev N., Cruz A.A.: Allergic Rhinitis and its Impact on Asthma. (ARIA) 2008 update (in collaboration with the World Health Organization, GA(2)LEN and AllerGen). Allergy. 2008; 63 (86): 8-160.

2. Bousquet J., Schünemann H.J., Samolinski B. et al.:. Allergic Rhinitis and its Impact on Asthma (ARIA): achievements in 10 years and future needs. J. Allergy Clin. Immunol. 2012; 130 (5): 1049-1062.

3. Samoliński B., Raciborski R., Lipiec A. et al.: Epidemiologia chorób alergicznych w Polsce ECAP. Alergologia Polska - Polish Journal of Allergology. 2014; 1 (1): 10-18

4. $\quad$ Rochat M.K., Illi S., Ege M.J., Lau S., Keil T., Wahn U., von Mutius E.: Multicentre Allergy Study (MAS) group. Allergic rhinitis as a predictor for wheezing onset in school-aged children. J. Allergy Clin. Immunol. 2010; 126 (6): 1170-1175.

5. Samoliński B., Arcimowicz M. (red.): Polskie Standardy Leczenia Nieżytów Nosa (PoSLeNN). Alergologia Polska. 2013 ; 1 : 1-167.

6. Brożek J.L., Bousquet J., Baena-Cagnani C.E. et al.: Global Allergy and Asthma European Network; Grading of Recommendations Assessment, Development and Evaluation Working Group. Allergic Rhinitis and its Impact on Asthma (ARIA) guidelines: 2010 revision. J. Allergy Clin. Immunol. 2010; 126 (3): 466-476.

7. Brożek J.L., Bousquet J., Agache I. et al.: Allergic Rhinitis and its Impact on Asthma (ARIA) guidelines - 2016 revision. J. Allergy Clin. Immunol. 2017; 140 (4): 950-958. Doi: 10.1016/j.jaci.2017.03.050.

8. Hellings P.W., Fokkens W.J., Akdis C. et al.: Uncontrolled allergic rhinitis and chronic rhinosinusitis: where do we stand today? Allergy. 2013 ; 68 (1): 1-7.

9. Rapiejko P., Stankiewicz W., Szczygielski K., Jurkiewicz D.: Threshold pollen count necessary to evoke allergic symptoms. Otolaryngol. Pol. 2007; 61 (4): 591-594.

10. Jurkiewicz D., Ligęziński A., Zawisza E., Lipiec A., Rapiejko P., Zielnik B., Samoliński B.: The influence of air pollution on the threshold exposure concentration allergenic pollen grains. Otolaryngol. Pol. 1997; 51 (22): 544-546.

11. Ambient (outdoor) air quality and health. Http://www.who.int/mediacentre/factsheets/fs313/en/; dostęp 2017-03-07.

12. Złotkowska R.: Wpływ zanieczyszczeń powietrza na zdrowie. Materiały pokonferencyjne. Katowice $2017: 11$.

13. Kubica K.: Zanieczyszczenia powietrza, ich główne źródła. Sytuacja Polski na tle Europy. Materiały pokonferencyjne: Wpływ zanieczyszczeń powietrza na zdrowie. Katowice 2017: 5-7.

14. Household air pollution and health. Http://www.who.int/mediacentre/factsheets/fs292/en/; dostęp 2017-03-07.

15. Skotak K.: Oddziaływanie pyłu zawieszonego na środowisko. Wpływ na zdrowie ludzi. W: Pyły drobne w atmosferze. Red Juda-Rezler K., Toczko B.: Biblioteka Monitoringu Środowiska. Warszawa 2016: 75-83.

16. Posniak M., Jankowska E., Szewczyńska M.: Szkodliwość spalin dla zdrowia człowieka. W: Zagrożenia spalinami silników Diesla. Państwowy Instytut Badawczy. Warszawa 2010: 8-9.

17. Samoliński B., Sybilski A.J., Raciborski F. et al: Prevalence of rhinitis in Polish population according to the ECAP (Epidemiology of Allergic Disorders in Poland) study. Otolaryngol. Pol. 2009; 63 (4): 324-330.

18. D’Amato G., D’Amato M.: Respiratory allergy (rhinitis and asthma), aeroallergens and other trigger factors (climate change and air pollution). Momento Medico. Salerno 2016: 59-69.

19. Hoek G., Pattenden S., Willers S. et al.: PM 10, and children's respiratory symptoms and lung function in the PATY study. Eur. Respir. J. $2012 ; 40$ (3): 538-547. 
20. D'Amato G.: Effects of climatic changes and urban air pollution on the rising trends of respiratory allergy and asthma. Multidiscip. Respir. Med. $2011 ; 6$ (1): 28-37.

21. De Marco R., Poli A., Ferrari M. et al.: The impact of climate and traffic-related NO2 on the prevalence of asthma and allergic rhinitis in Italy. Clin. Exp. Allergy. 2002; 32 (10): 1405-1012.

22. Pattenden S., Hoek G., Braun-Fahrländer C. et al.: NO2 and children's respiratory symptoms in the PATY study. Occup. Environ. Med. 2006 ; 63 (12): 828-835.

23. Riedl M., Diaz-Sanchez D.: Biology of diesel exhaust effects on respiratory function. J. Allergy Clin. Immunol. 2005; 115: 221-228.

24. Bowatte G., Lodge C., Lowe A.J. et al.: The influence of childhood traffic-related air pollution exposure on asthma, allergy and sensitization: a systematic review and a meta-analysis of birth cohort studies. Allergy. 2015; 70: 245-256.

25. Bowatte G., Lodge C.J., Knibbs L.D.: Traffic-related air pollution exposure is associated with allergic sensitization, asthma, and poor lung function in middle age. J. Allergy Clin. Immunol. 2016; 139 (1): 122-129.

26. Nell A.E., Diaz-Sanchez D., Ng D. et al.: Enhancement of allergic inflammation by the interaction betewwen diesel exhaust particles and the immune system. J. Allergy Clin. Immunol. 1998; 102 (41): 539-554.

27. Porebski G., Woźniak M., Czarnobilska E.: Residential proximity to major roadways is associated with increased prevalence of allergic respiratory symptoms in children. Ann. Agric. Environ. Med. 2014; 21 (4): 760-766.

28. Ghiani A., Aina R., Asero R. et al.: Ragweed pollen collected along high-traffic roads shows a higher allergenicity than pollen sampled in vegetated areas. Allergy. 2012; 67 (7): 887-894.

29. Beck I., Jochner S., Gilles S. et al.: High environmental ozone levels lead to enhanced allergenicity of birch pollen. PLoS One. 2013 ; 8 (11): e80147.

30. Obersteiner A., Gilles S., Frank U.: Pollen-Associated Microbiome Correlates with Pollution Parameters and the Allergenicity of Pollen. PLoS One. 2016; $24 ; 11(2): 149545$.

31. Hansen J.W., Thomsen S.F., Nolte H., Backer V.: Rhinitis: a complication to asthma. Allergy. $2010 ; 65$ (7): $883-888$.

32. Fokkens W., Lund V., Mullol J. et al.: European position paper on rhinosinusitis and nasal polyps. Rhinol. Suppl. 2012 ; (23): 1-298.

33. Hellings P.W., Muraro A., Fokkens W., Mullol J., Bachert C., Canonica G.W., Price D., Papadopoulos N., Scadding G., Rasp G., Demoly P., Murray R., Bousquet J.: A common language to assess allergic rhinitis control: results from a survey conducted during EAACI 2013 Congress. Clin. Transl. Allergy. 2015 ; 27 (5): 36.

34. Takeda K., Takeno S., Hirakawa K., Ishino T.: Expression and distribution of glucocorticoid receptor isoforms in eosinophilic chronic rhinosinusitis. Auris Nasus Larynx. 2010; 37 (6): 700-707.

35. Kakumanu S., Glass C., Craig T.: Poor sleep and daytime somnolence in allergic rhinitis: significance of nasal congestion. Am. J. Respir. Med. 2002; 1: 195-200.

36. Jee H.M., Kim K.W., Kim C.S., Sohn M.H., Shin D.C., Kim K.E.: Prevalence of asthma, rhinitis and eczema in Korean children using the International Study of Asthma and Allergies in Childhood (ISAAC) Questionnaires. Pediatr. Allergy Respir. Dis. 2009; 19: 165-172.

37. Ibiapina Cda C., Sarinho E.S., Camargos P.A., Andrade C.R., Cruz Filho A.A.: Allergic rhinitis: epidemiological aspects, diagnosis and treatment. J. Bras. Pneumol. 2008; 34 (4): 230-240.

38. Tanner L.A., Reilly M., Meltzer E.O., Bradford J.E., Mason J.: Effect of fexofenadine HCI on quality of life and work, classroom and daily activity impairment in patients with seasonal allergic rhinitis. Am. J. Manag. Care. 1999; 5 (4): 235-247.

39. Schoenwetter W.F., Dupclay L. Jr., Appajosyula S., Botteman M.F., Pashos C.L.: Economic impact and quality-of-life burden of allergic rhinitis. Curr. Med. Res. Opin. 2004; 20 (3): 305-317.

40. Scadding G.K., Richards D.H., Price M.J.: Patient and physician perspectives on the impact and management of perennial and seasonal allergic rhinitis. Clin. Otolaryngol. Allied Sci. 2000; 25 (6): 551-557.

41. Valovirta E., Myrseth S.E., Palkonen S.: The voice of the patients: allergic rhinitis is not a trivial disease. Curr. Opin. Allergy Clin. Immunol. 2008; 8 (1): 1-9.

42. Chang P.P., Ford D.E., Mead L.A., Cooper-Patrick L., Klag M.J.: Insomnia in young men and subsequent depression. The Johns Hopkins Precursors Study. Am. J. Epidemiol. 1997; 146 (2): 105-114.

43. Owens J., Opipari L., Nobile C., Spirito A.: Sleep and daytime behavior in children with obstructive sleep apnea and behavioral sleep disorders. Pediatrics. 1998; 102 (5): 1178-1184.

44. Gozal D.: Sleep-disordered breathing and school performance in children. Pediatrics. 1998; 102 (3 Pt 1): 616-620.

45. Hughes K., Glass C., Ripchinski M., Gurevich F., Weaver T.E., Lehman E. et al.: Efficacy of the topical nasal steroid budesonide on improving sleep and daytime somnolence in patients with perennial allergic rhinitis. Allergy. 2003; 58 (5): 380-385.

46. Mansfield L.E., Diaz G., Posey C.R., Flores-Neder J.: Sleep disordered breathing and daytime quality of life in children with allergic rhinitis during treatment with intranasal budesonide. Ann. Allergy Asthma Immunol. 2004; 92 (2): 240-244.

47. Nathan R.A.: The burden of allergic rhinitis. Allergy Asthma Proc. 2007; 28 (1): 3-9.

48. Meltzer E.O.: Quality of life in adults and children with allergic rhinitis. J. Allergy Clin. Immunol. $2001 ; 108$ (1): 45-53.

49. Stahl S.M.: Prescriber's Guide Essential Psychopharmacology. Cambridge University Press, Cambridge, 2017.

50. Hansten P.D., Horn J.R.: Top 100 Drug Interactions 2017. H\&H Publications, Freeland 2017.

51. Hochadel M.A.: Mosby's Drug Reference for Health Proffesions. Elsevier, St Louis 2016.

52. Kostka-Trąbka E., Woroń J.: Interakcje leków w praktyce klinicznej. Wydawnictwo Lekarskie PZWL, Warszawa 2011.

53. Preston C.L.: Stockley's Drug Interactions 2015. Pharmaceutical Press, London, 2014. 
54. Paśko P., Rodacki T., Rodacka-Domagała T. et al.: Second generation H1-antihistamines interactions with food and alcohol. Biomedicine \& Pharmacotherapy 2017; 93, 27-39.

55. Mahatme M.S., Dakhala G.N., Tadke K. et al.: Comparisons of efficacy, safety and cost-effectiveness of montelukast-cetirizine and montelukast-fexofenadine in patients of allergic rhinitis. Indian. J. of Pharmacology. 2016.

56. Recto M.T., Gabriel M.T., Kulthanan K. et al.: Selecting optimal second-generation antihistamines for allergic rhinitis and urticarial in Asia. Clin. Mol. Allergy. 2017; 15: 19. Doi: 10.1186/s12948-017-0074-3.

57. Zuberbier T., Aberer W., Asero R. et al.: The EAACI/GA(2)LEN/EDF/WAO guideline for the definition, classification, diagnosis, and management of urticaria: the 2013 revision and update. Allergy. 2014; 69: 868-887.

\section{Word count: 5670 Tables: 1 Figures: 1 References: 57}

Access the article online: DOI: 10.5604/01.3001.0011.8057 Table of content: https://otolaryngologypl.com/issue/11091

Corresponding author: Piotr Rapiejko; Department of Otolaryngology with Division of Cranio-Maxillo-Facial Surgery in Military Institute of Medicine, Warsaw, Poland; E-mail: piotr@rapiejko.pl

Copyright ( 2018 Polish Society of Otorhinolaryngologists Head and Neck Surgeons. Published by Index Copernicus Sp. z o.o. All rights reserved.

Competing interests: The authors declare that they have no competing interests

Cite this article as: Rapiejko P., Jurkiewicz D., Pietruszewska W., Zielnik-Jurkiewicz B., Woron J. Lipiec A.; Treatment strategy of allergic rhinitis in the face of modern world

threats; Otolaryngol Pol 2018; $72(2): 1-12$ 